\title{
泌尿器・腎
}

\section{Robotic surgery for kidney cancer}

\author{
田中一志，藤澤正人 \\ 神戸大学大学院医学研究科外科系講座腎泌尿器科学分野
}

\section{Kazushi Tanaka, Masato Fujisawa}

Division of Urology, Department of Surgery Related, Kobe University Graduate School of Medicine

\begin{abstract}
The da Vinci Surgical System is the high-quality robotic system used for urologic surgeries. This system offers a number of potential advantages, including magnified stereoscopic vision, elimination of tremor, and fully articulating instruments. Compared to conventional laparoscopic surgery, the da Vinci Surgical System may facilitate more accurate and safe operations. These refinements may help to reduce the technical challenge for kidney surgery. In this article, we describe our technique and literature review for robot-assisted partial nephrectomy including selective artery clamping method.
\end{abstract}

\section{Key words}

Kidney cancer, partial nephrectomy, robotic surgery

\section{1.はじめに}

現在, 腎腫瘍と診断される $60 \%$ 以上が $4 \mathrm{~cm}$ 以下の 小径腫瘍である ${ }^{1)}$. 小径腎癌においては腎部分切除術 が根治的腎摘術に比べ, 癌制御の遜色なく，腎機能お よび生命予後において良好であることから第一選択 とされている ${ }^{2)}$. 従来, 腎部分切除術は開放性手術で 行われていたが，より低侵襲な手術として 1993 年に Winfield らが腹腔鏡下部分切除術を報告し ${ }^{3)}$ ，本邦に おいても同手術が行われるようになった。しかしな がら, 腹腔内での切除, 縫合といった高度な技術が必 要であり，広く普及していく上での妨げとなってい る。手術支援ロボット (da Vinci Surgical System : 以下 da Vinci）は, 高解像度 3D 視野, 多自由度鉗子, 手振 れ防止機構などの良好な操作性，といった特徵を兼 ね備えており，腎部分切除術において有用であると 考えられる。事実 Gettmanらがロボット支援腎部分 切除術を報告して以来 ${ }^{4)}$ ，様々な施設でその良好な治 療成績が報告されており ${ }^{5)-7)}$, 腹腔鏡手術との比較に おいても良好な成績が報告されている（Table 1 $)^{8)-13)}$ 。本稿ではロボット支援腎部分切除術につい
て，文献的考察に加え選択的動脈遮断法を含む我々 の手技を提示する。

\section{2. 神戸大学での方法}

1）体位, ポート位置とアプローチ

体位は側臥位で, 腫瘍の部位によって経腹膜到達 法, 後腹膜到達法のいずれかを選択している。原則と して腹側の腫瘍（外側や上極や下極も含む）は経腹膜 到達法で，背側の腫瘍は後腹膜到達法で行っている. 経腹膜到達法では, ペイシェントカートは患者の背 側からドッキングし，右側であれば 6 本のトロカー を左側であれば 5 本のトロカーを用いる（Fig.1）。後 腹膜到達法では, ペイシェントカートは患者の頭側 からドッキングし，4本または 5 本のトロカーを挿入 する（Fig.2）。我々の施設では原則としてロボットは 3 本アームで行っている.

\section{2）術野の展開}

通常のロボット支援下腎部分切除同様, 経腹膜到 達法であれば腎前面から, 後腹膜到達法であれば腎 
Table 1 ロボット支援腎部分切除術と腹腔鏡下腎部切除術との比較

\begin{tabular}{|c|c|c|c|c|c|c|c|c|c|c|}
\hline 報告者 & $\begin{array}{c}\text { 報告年 } \\
\text { (年) }\end{array}$ & 術式 & $\mathrm{n}$ & $\begin{array}{c}\text { 腫瘍径 } \\
(\mathrm{cm})\end{array}$ & $\begin{array}{c}\text { 手術時間 } \\
(\min )\end{array}$ & 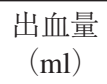 & $\begin{array}{l}\text { WIT } \\
(\min )\end{array}$ & $\begin{array}{c}\text { 断端陽性 } \\
(\%)\end{array}$ & $\begin{array}{c}\text { 合併症 } \\
(\%)\end{array}$ & 文献 \\
\hline \multirow[t]{2}{*}{ Benway et al } & \multirow[t]{2}{*}{2009} & RPN & 129 & 2.9 & 189 & $155^{*}$ & $19.7^{*}$ & 3.9 & 8.5 & \multirow[t]{2}{*}{8} \\
\hline & & LPN & 118 & 2.6 & 174 & $196^{*}$ & $28.4^{*}$ & 0.8 & 10.2 & \\
\hline \multirow[t]{2}{*}{ Haber et al } & \multirow[t]{2}{*}{2010} & RPN & 75 & 2.8 & 200 & $323^{*}$ & 18.2 & 0 & 16 & \multirow[t]{2}{*}{9} \\
\hline & & LPN & 75 & 2.5 & 197 & $222^{*}$ & 20.3 & 0 & 13.3 & \\
\hline \multirow{2}{*}{$\begin{array}{l}\text { Long et al } \\
\text { RN score } \geqq 7\end{array}$} & \multirow[t]{2}{*}{2012} & RPN & 199 & 3.8 & $196.9^{*}$ & 280 & 22.4 & 2 & 8.3 & \multirow[t]{2}{*}{10} \\
\hline & & LPN & 182 & 4 & $240.7^{*}$ & 325 & 23.2 & 1 & 18.3 & \\
\hline \multirow[t]{2}{*}{ Ellison et al } & \multirow[t]{2}{*}{2012} & RPN & 108 & 2.9 & $215^{*}$ & 368 & 26.8 & 7 & 輸血 6\% & \multirow[t]{2}{*}{11} \\
\hline & & LPN & 108 & 2.7 & $162^{*}$ & 400 & 28.2 & 7 & 輸血 7\% & \\
\hline \multirow[t]{2}{*}{ Mullins et al } & \multirow[t]{2}{*}{2012} & RPN & 105 & 2.1 & $165^{*}$ & $100^{*}$ & $15^{*}$ & 3.8 & 輸血 0\% & \multirow[t]{2}{*}{12} \\
\hline & & LPN & 102 & 2.2 & $180^{*}$ & $200^{*}$ & $20^{*}$ & 1 & 輸血 $4.9 \%$ & \\
\hline \multirow[t]{2}{*}{ Lee BR et al } & \multirow[t]{2}{*}{2013} & RPN & 199 & 3.18 & 172.6 & 224.8 & 19.7 & & & \multirow[t]{2}{*}{13} \\
\hline & & LPN & 176 & 2.7 & 168.7 & 326.6 & 35.2 & & & \\
\hline
\end{tabular}

*は有意差あり

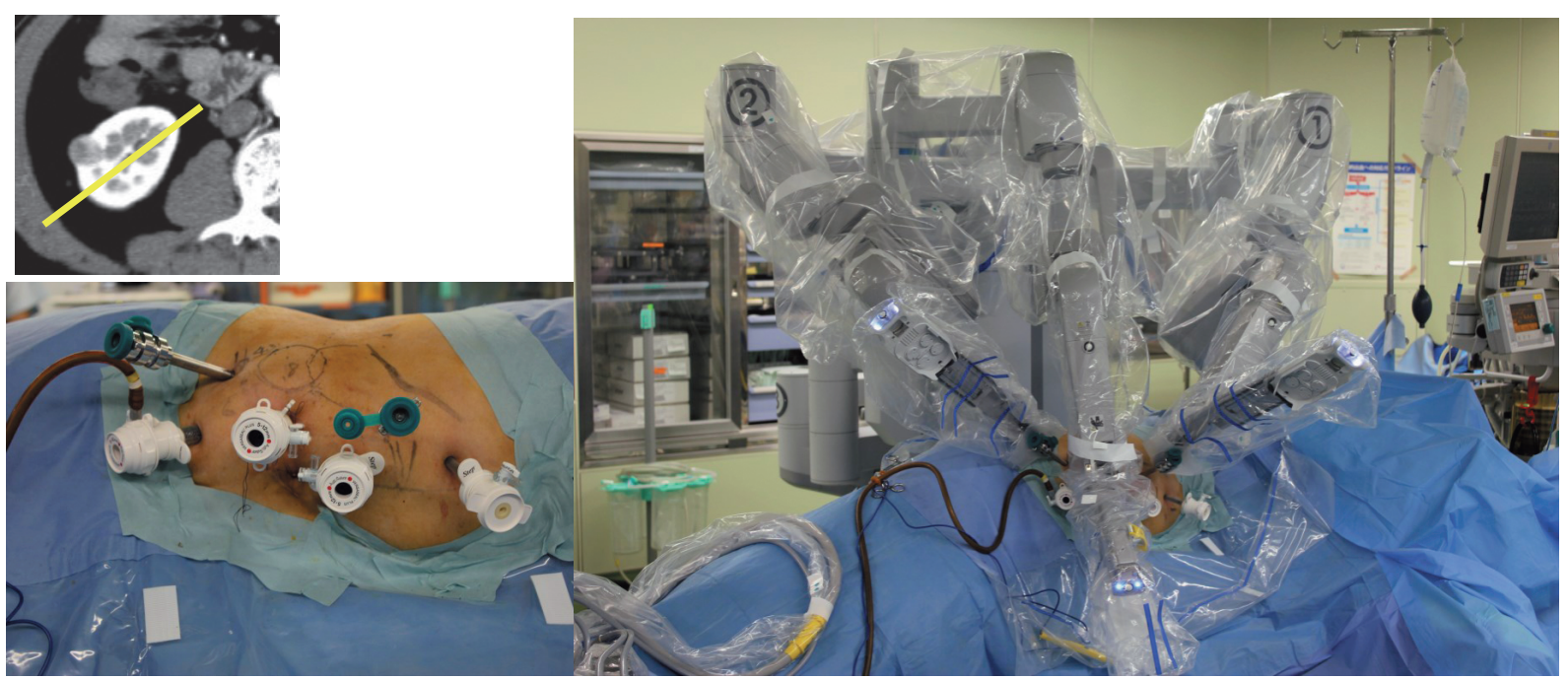

Fig.1 経腹膜到達法の, CT 画像とポート位置と da Vinciのドッキングした様子.

後面から展開し，腎茎部，腎門部を同定する。選択的 動脈遮断を行うのであれば，必ずしも動脈の本幹を 露出する必要はなく，選択的に阻血する血管が同定 できた場合にはその血管のみ剥離を行う。

\section{3）超音波での確認（Fig.3）}

da Vinci 用超音波プローブを用い腫瘍の境界を確 認し, 十分な surgical margin が得られる部分を確認す る。その像は Tile Pro を用いコンソールに投影してい る.我々の施設では術前に $3 \mathrm{D}$ 構築像を $\mathrm{PC}$ で作成し, 同様に Tile Pro を用いコンソールに投影している.

\section{4) マーキング}

上述したUS の所見にあわせてモノポーラーカー ブドシザーズを用い電気凝固でマーキングしていく. 原則全周性に行うが上極の腫瘍などでは一部で全周 には剥離できない状態があり，その際には腎周囲を 剥離後に可能な部分のマーキングを行うこととして いる.

\section{5）腎動脈遮断（Fig.4）}

あらかじめ腎動脈には血管テープを通しておき 当院では静脈 clamp は行わず, 動脈のみの阻血を行 う. 腫瘍への動脈が同定でき, 選択的動脈阻血が可能 

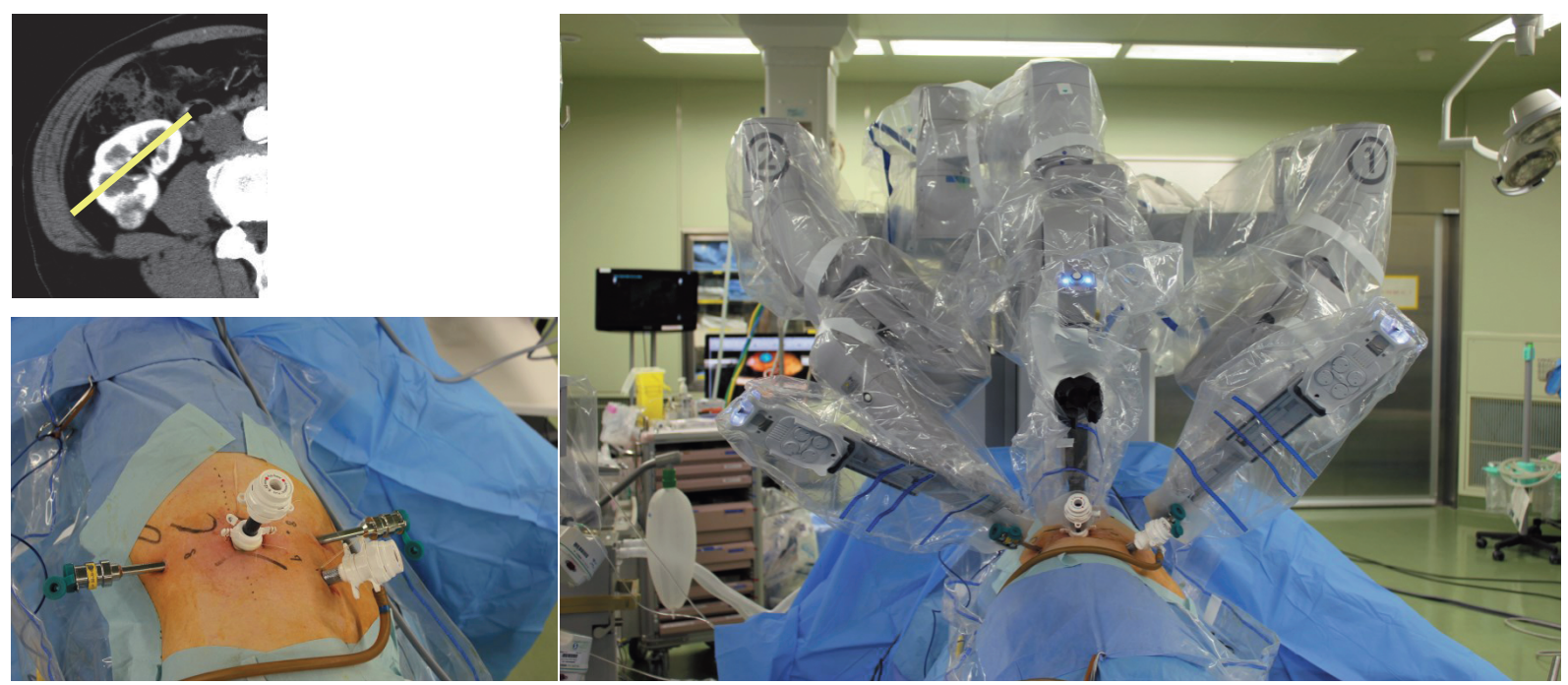

Fig.2 後腹膜到達法の, CT 画像とポート位置と da Vinci のドッキングした様子

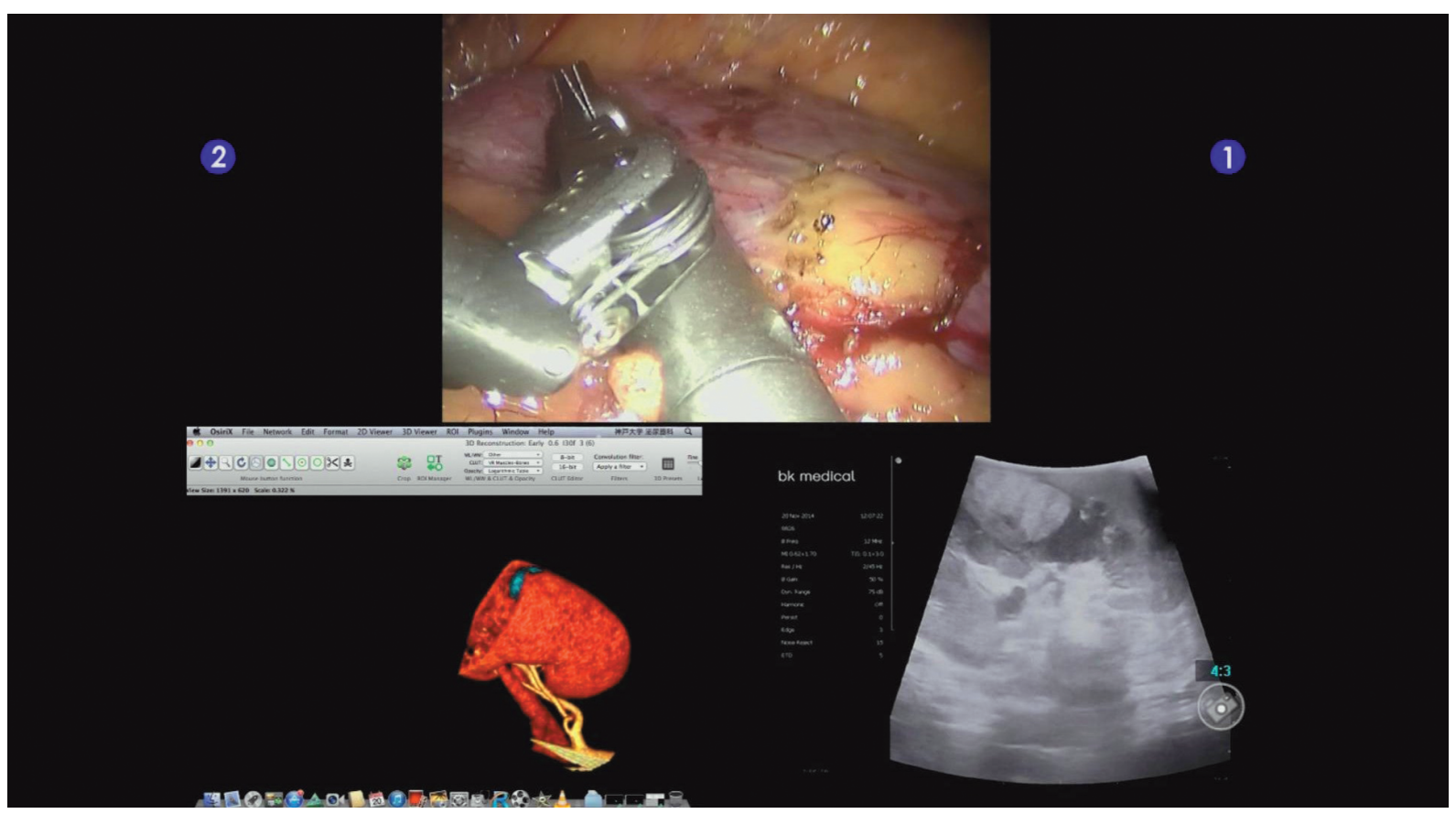

Fig.3 サージョンコンソールから見た術中エコー所見. 上段が術野でロボット用エコープローブを操作している。下段 左が 3D 構築画像. 下段右が超音波画像.

な症例については, 腫瘍血管のみを遮断する選択的 動脈遮断を行う.

\section{6) 切開（Fig.5）}

モノポーラーカーブドシザーズを用い, 電気凝固 は行わず, cold dissection を行い, 腫瘍への切り込み がないのを確認しながら切除する.

\section{7）縫合}

縫合は 2 層縫合を行う。深部縫合（1層目）で, 止 血および開放された尿路の修復を行い，2 層目で腎被 膜から腎実質の縫合を行う. 鉗子は右手をラージニー ドルドライバー (針持器) とし, 左手はフェネストレ イティッドバイポーラー鈿子としている. 深部縫合 $(1$ 層目）には 3-0 VLoc V-20 $15 \mathrm{~cm}$ を用い, 腎被膜, 腎 


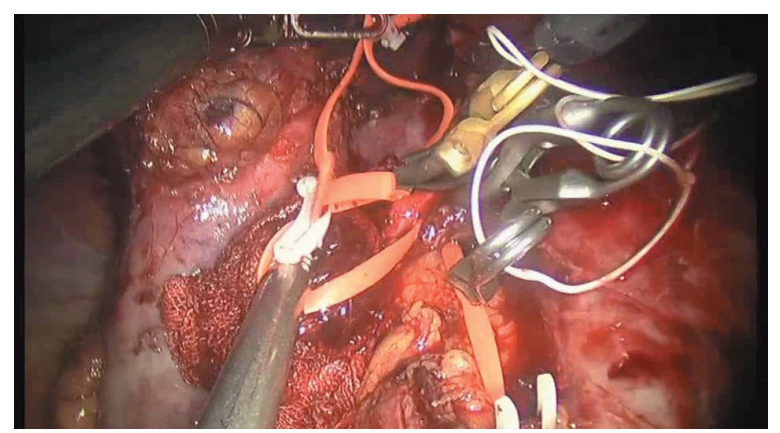

Fig.4 3 本の腎動脈の分枝を腹腔鏡用ブルドックでクラ ンプしたところ.

実質縫合（2 層目）には 2-0 V-Loc GS-21 $30 \mathrm{~cm}$ を用 い, 共に端のループの部分には Lapra-Ty と Hemolock（L) をつけている.カメラは $0^{\circ}$ まな $30^{\circ}$ down, $30^{\circ}$ up のいずれか見えやすいものを用いる.

\section{8) Unclamp}

Unclamp し止血を確認する.

\section{9）追加止血}

表面からの出血に対してはガーゼで圧迫を行い， 止血する. 大部分の症例ではこれでコントロール可 能である。必要に応じて 2-0 Vicryl で追加縫合を行 う。さらに縫合部にタコシールを貼付しフィブリン 糊を塗布する。腎周囲脂肪織が余っている場合, 切除 部を覆うようにこれを縫合する。

\section{3. 神戸大学での成績}

当院で 2014 年 9 月までに行った 58 例について検 討した。性別は男性 47 例, 女性 11 例, 年齢の平均值 61.1 歳, 患側は右側が 41 例, 左側が 17 例であった。 経腹膜到達法と後腹膜到達法をそれぞれ 40 例, 17 例 に施行した。腫瘍径の中央值は $2.9 \mathrm{~cm}$ で，部分阻血 を 32 例に行った。手術時間の平均值は 302.7 分, 阻 血時間の平均值は 21.0 分, 出血量の平均值は 44.1 $\mathrm{ml}$ であった。術前の $\mathrm{Cr}$ 值, eGFR はそれぞれ 0.89 $\mathrm{mg} / \mathrm{dL}, \quad 68.7 \mathrm{~mL} / \mathrm{min} / 1.73 \mathrm{~m}^{2}$, 術後の $\mathrm{Cr}$ 值, eGFR はそれぞれ $0.96 \mathrm{mg} / \mathrm{dL}, 63.6 \mathrm{~mL} / \mathrm{min} / 1.73 \mathrm{~m}^{2}$, 術前 後の変化量は $\mathrm{Cr}, \mathrm{eGFR}$ それぞれ $0.07 \mathrm{mg} / \mathrm{dL},-5.1$ $\mathrm{mL} / \mathrm{min} / 1.73 \mathrm{~m}^{2}$ であった。

\section{4. 選択的腎動脈遮断}

腎部分切除術において最大限に腎機能を温存する

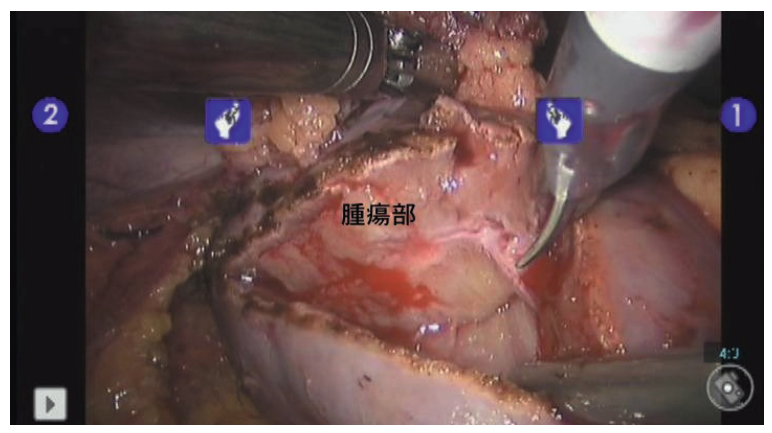

Fig.5 腫瘍に切り込んでないかを確認しながら cold dissectionを行っている.

には，無阻血での方法が最も適切であると考えられ るが, 出血への対応など特に腎門部腫瘍など太い血 管に近い腫瘍では出血のコントロールは困難で，さ らに術野の確保が困難となり切除断端の確保などに 問題が生じる可能性がある ${ }^{14)}$. 術後の腎機能温存と 術野の確保の両立を達成する方法として, 前述した ように選択的腎動脈遮断の方法が試みられている。 術前に腫瘍への腎動脈の分枝を確認しておき, 術中 にこれらの血管を同定し，その血管のみを選択的に 阻血し, 腫瘍部以外の腎実質は無阻血で腫瘍を切除 する方法である。 Gillらが “Zero ischemia”として腹 腔鏡およびロボット手術で良好な成績を報告してい $3^{15), 16)}$. 我々の経験から特に手術支援ロボット（da Vinci）はその特徴から繊細な操作が可能であり，有 用であると考えられる ${ }^{16)}$.

\section{5. 術前シミュレーション}

選択的腎動脈遮断を行うには, 術前に腫瘍への血 管を含む腫瘍と腎血管の位置関係を把握し, 同定し ておく必要がある。神戸大学では thin sliceの CT data から画像処理を行い, 3D 構築画像を OsiriX を用いて 作成している. Fig.6に示すように3D 画像を構築し, 腫瘍への血管を同定し，術前にシミュレーシュンを 行っておく．腫瘍血管が腎実質外で同定・clampでき るものに対して，選択的阻血を選択する。腎実質内の 分枝のみしか同定できない場合には，選択的阻血は 断念し, 全阻血を行う。症例によっては3D モデルを 作成し，腫瘍と血管の位置関係を確認する場合もあ る（Fig.7）。立体として直感的に把握でき，その点で は有用であるが, 現時点では十分細部まで血管の描 出は再現できない. その為, 最終的には血管の同定は $3 \mathrm{D}$ 構築画像で確認している. 


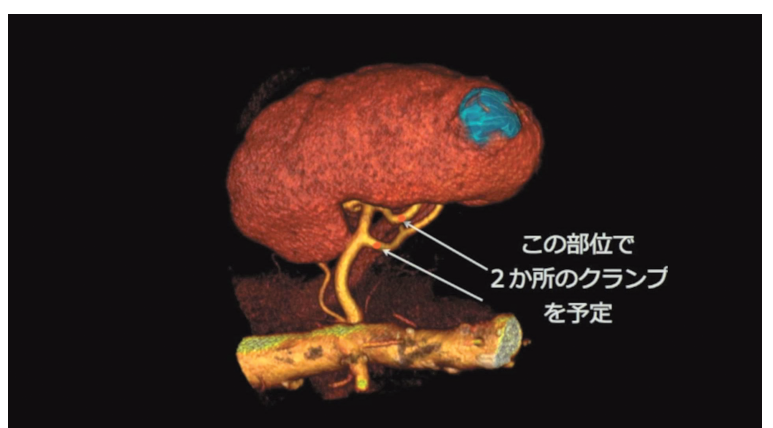

Fig.6 3D 構築画像. この症例では腫瘍への 2 本の腎動脈 の分枝をクランプする.

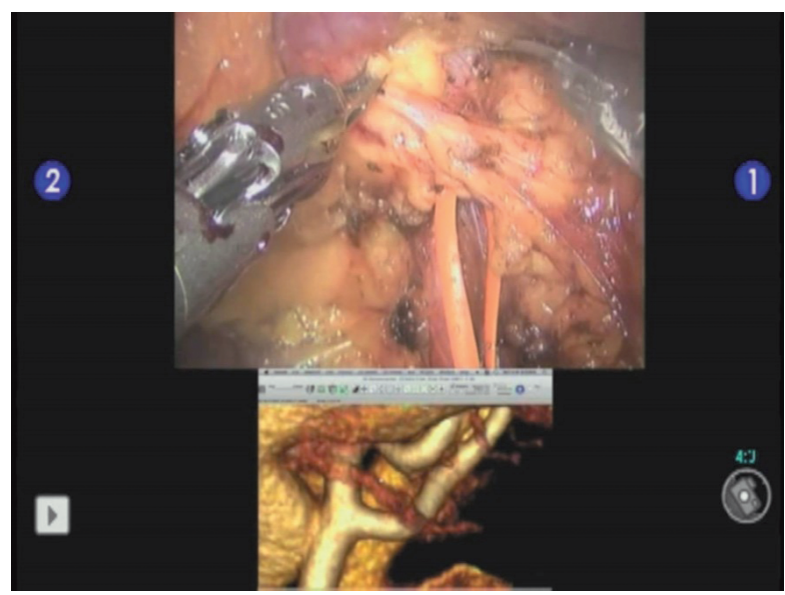

Fig.8 術中ナビゲーション. 左はサージョンコンソールからみた像で, Tile Pro で 3D 構築画像を挿入している. 右は手 術室内の様子で，手前の助手が 3D 画像を操作している.

\section{6. 術中ナビゲーション}

上記方法で作成した画像を術中に Tile Pro を用い てサージョンコンソールに挿入し，術者はそれらを 確認しながら腫瘍への血管を同定する（Fig.8）。腎門 部の血管に対してもダイレクトのアプローチが可能 となる。さらに前述したように術中の超音波画像を 挿入し, これらの画像と術野の所見から, 切除すべき 腫瘍, 阻血する動脈, 切除範囲を決定する。超音波プ ローブについては, 導入当初は腹腔鏡用超音波プロー ブを用い助手が操作していたが，現在は前述したよ うにロボット手術用の超音波プローブを用い, 術者 が操作を行っている。

\section{おわりに}

高解像度 $3 \mathrm{D}$ 視野, 多自由度鉗子, 手振孔防止機構, といった特徴をもった da Vinci は腎部分切除術，特 に選択的動脈遮断法において有用であると考えられ
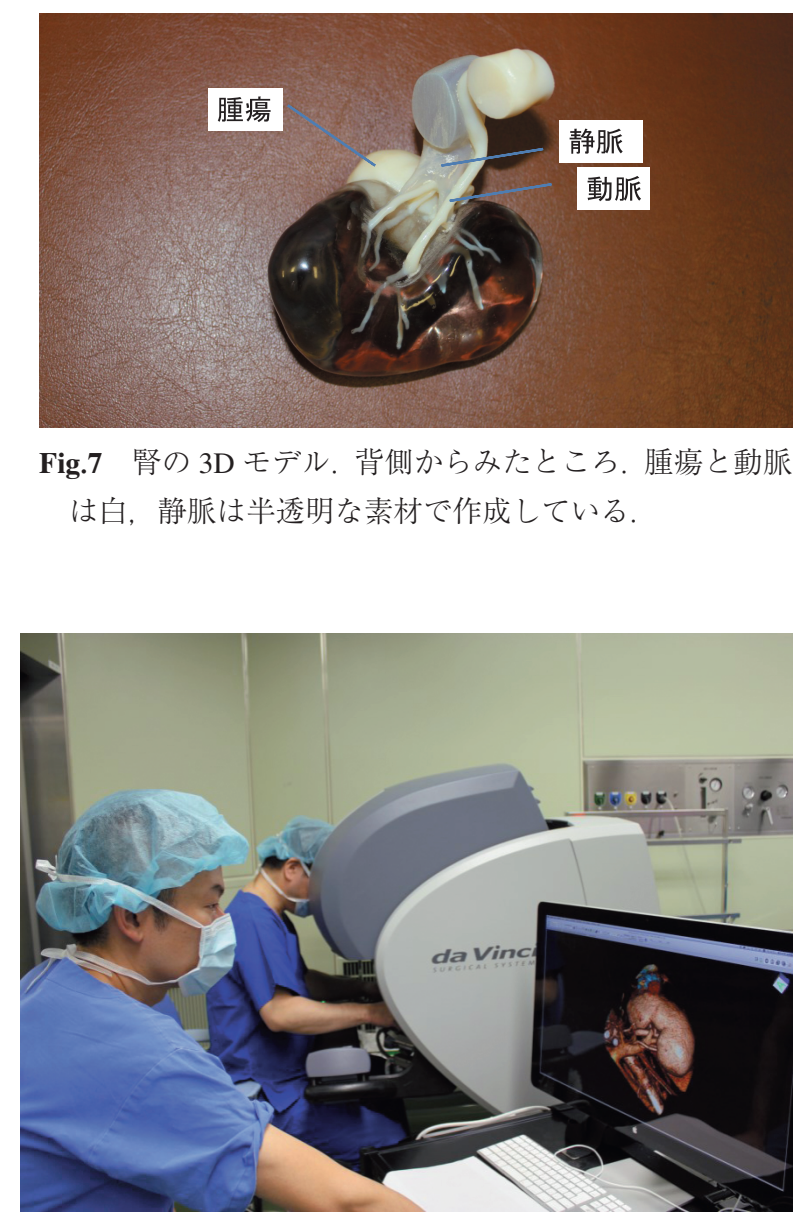

Fig.7 腎の 3D モデル。背側からみたところ. 腫瘍と動脈 は白，静脈は半透明な素材で作成している。 
918.

5) Kaouk JH, Hillyer SP, Autorino R, et al. 252 robotic partial nephrectomies: evolving renorrhaphy technique and surgical outcomes at a single institution. Urology 2011;78(6):13381344.

6) Benway BM, Bhayani SB, Rogers CG, et al. Robot assisted partial nephrectomy versus laparoscopic partial nephrectomy for renal tumors: a multi-institutional analysis of perioperative outcomes. J Urol 2009;182(3):866-872.

7) Pierorazio PM, Patel HD, Feng T, et al. Robotic-assisted versus traditional laparoscopic partial nephrectomy: comparison of outcomes and evaluation of learning curve. Urology 2011;78 (4) :813-819.

8) Benway BM, Bhayani SB, Rogers CG, et al. Robot assisted partial nephrectomy versus laparoscopic partial nephrectomy for renal tumors: a multi-institutional analysis of perioperative outcomes. J. Urol 2009;182:866-872.

9) Haber GP, White WM, Crouzet S, et al. Robotic versus laparoscopic partial nephrectomy: single-surgeon matched cohort study of 150 patients. Urology 2010;76:754-758.

10) Long JA, Yakoubi R, Lee B, et al. Robotic versus laparoscopic partial nephrectomy for complex tumors: comparison of perioperative outcomes. Eur Urol 2012;61:1257-1262.

11) Ellison JS, Montgomery JS, Wolf JS Jr, et al. A matched comparison of perioperative outcomes of a single laparoscopic surgeon versus a multisurgeon robot$^{-}$assisted cohort for partial nephrectomy. J Urol 2012;188:45-50.

12) Mullins JK, Feng T, Pierorazio PM, et al. Comparative analysis of minimally invasive partial nephrectomy techniques in the treatment of localized renal tumors. Urology 2012;80:316-321.

13) Wang L, Lee BR. Robotic partial nephrectomy: current technique and outcomes. Int J Urol 2013;20:848-859.

14) Wszolek MF, Kenney PA, Lee Y, et al. Comparison of hilar clamping and non-hilar clamping partial nephrectomy for tumours involving a solitary kidney. BJU Int 2011;107(12): 1886-1892.

15) Gill IS, Patil MB, Abreu AL, et al. Zero ischemia anatomical partial nephrectomy: a novel approach. J Urol 2012;187 (3) :807814.

16) Furukawa J, Miyake H, Tanaka K, et al. Console-integrated realtime three-dimensional image overlay navigation for robot $^{-}$ assisted partial nephrectomy with selective arterial clamping: early single-centre experience with 17 cases. Int J Med Robot 2004;10 (4):385-390. 